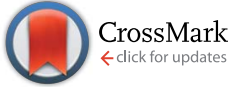

Cite this: RSC Adv., 2017, 7, 4190

Received 1st November 2016 Accepted 30th December 2016

DOI: $10.1039 /$ c6ra26120e

www.rsc.org/advances

\section{Persistent luminescence in the self-activated $\mathrm{K}_{2} \mathrm{Zr}\left(\mathrm{BO}_{3}\right)_{2}$}

\author{
Guifang Ju, ${ }^{*}$ Yihua Hu, Li Chen, Yahong Jin and Yang Li
}

This study reports a cyan emitting self-activated persistent phosphor $\mathrm{K}_{2} \mathrm{Zr}\left(\mathrm{BO}_{3}\right)_{2}$. The material is synthesized by solid state reaction method. The persistent phosphor was characterized in detail by $\mathrm{X}$-ray powder diffraction, diffuse reflectance, photoluminescence, persistent luminescence and thermoluminescence spectra. After UV irradiation, the $\mathrm{K}_{2} \mathrm{Zr}\left(\mathrm{BO}_{3}\right)_{2}$ phosphor shows a cyan persistent luminescence dominating at $\sim 485 \mathrm{~nm}$. Both the fluorescence and persistent luminescence are due to charge transfer emission from the central zirconium ion to oxygen in the ligand. The deconvolution of the thermoluminescence curve reveals that there are four traps responsible for the persistent luminescence. The depth of the dominant trap is $0.66 \mathrm{eV}$. Based on experimental results, the trapping and detrapping processes of the charge carriers are discussed. A rudimentary energy level scheme was proposed to explain the mechanisms of persistent luminescence as well as photoluminescence.

\section{Introduction}

Persistent luminescence is an optical phenomenon in which luminescence can persist for minutes and even days without energy sources. ${ }^{1-4}$ It is a special case of thermally stimulated luminescence at room temperature. The required energy is reserved from the excitation source earlier by either intrinsic or dopant induced traps.

Matsuzawa et al. reported the persistent luminescence in $\mathrm{SrAl}_{2} \mathrm{O}_{4}: \mathrm{Eu}^{2+}, \mathrm{Dy}^{3+}$ in $1996,{ }^{5}$ this aluminate was regarded as the first milestone of persistent phosphors. Thereafter, research of aluminates and silicates, e.g., $\mathrm{CaAl}_{2} \mathrm{O}_{4}: \mathrm{Eu}^{2+}, \mathrm{Nd}^{3+}, 6{ }^{6} \mathrm{Sr}_{4} \mathrm{Al}_{14} \mathrm{O}_{25}$ :$\mathrm{Eu}^{2+}, \mathrm{Dy}^{3+}$ (ref. 7) and $\mathrm{Sr}_{2} \mathrm{MgSi}_{2} \mathrm{O}_{7}: \mathrm{Eu}^{2+}, \mathrm{Dy}^{3+},{ }^{3}$ are particularly representative and the elites of these phosphors have been successfully commercialized and are widely used in a variety of fields, such as instruction signs, displays and decoration. ${ }^{9-11}$

Le Masne de Chermont et al. introduced persistent phosphors into the in vivo optical imaging field, ${ }^{\mathbf{1 2}}$ because persistent phosphors do not require real-time excitation, which can avoid tissue autofluorescence. In order to fit in the biological window, ${ }^{13}$ near-infrared persistent phosphors have received considerable attention. In 2011, Pan et al. reported the nearinfrared persistent luminescence from $\mathrm{Cr}^{3+}$-doped zinc gallogermanates. ${ }^{1}$ The after glow of this material can last amazing 360 h. $\mathrm{Zn}_{3} \mathrm{Ga}_{2} \mathrm{Ge}_{2} \mathrm{O}_{10}$ : $\mathrm{Cr}^{3+}$ can be taken as the second milestone of persistent phosphors. Besides $\mathrm{Zn}_{3} \mathrm{Ga}_{2} \mathrm{Ge}_{2} \mathrm{O}_{10}: \mathrm{Cr}^{3+}$, a lot of $\mathrm{Cr}^{3+}$-doped near-infrared persistent phosphors were also rare earth doped persistent phosphors boomed. $\mathrm{Eu}^{2+}$-activated

reported, most of them are gallates or gallogermanates, e.g., $\mathrm{ZnGa}_{2} \mathrm{O}_{4}: \mathrm{Cr}^{3+},{ }^{14} \mathrm{La}_{3} \mathrm{Ga}_{5} \mathrm{GeO}_{14}: \mathrm{Cr}^{3+}{ }^{15,16}$ and $\mathrm{LiGa}_{5} \mathrm{O}_{8}: \mathrm{Cr}^{3+} \cdot{ }^{17}$

Most phosphors are compositions of an activator (usually several percent) and a host. The activators have an incompletely filled shell which can provide certain energy levels. The energy levels are responsible to the absorption and emission of the phosphors. On the other hand, the host constituent ions only have complete shells; therefore the host is inert to visible light. However, some phosphors contain no activator. In other words, the activator concentration is $100 \%$. This kind of phosphors is known as self-activated phosphors. ${ }^{18,19}$ At present, some studies on self-activated persistent phosphors have been reported, including $\mathrm{Ba}_{2} \mathrm{TiP}_{2} \mathrm{O}_{9},{ }^{20} \mathrm{Ca}_{2} \mathrm{Ge}_{7} \mathrm{O}_{16}{ }^{21} \mathrm{Ca}_{2} \mathrm{ZrSi}_{4} \mathrm{O}_{12},{ }^{22} \mathrm{Na}_{5} \mathrm{YZrSi}_{6}$ $\mathrm{O}_{18}$ (ref. 23) and $\mathrm{CaZr}_{4}\left(\mathrm{PO}_{4}\right)_{6} \cdot{ }^{24}$ Although tungstates and vanadates are the well known self-activated phosphors, when it comes to self-activated persistent phosphors, zirconates are the main players.

The borate compound $\mathrm{K}_{2} \mathrm{Zr}\left(\mathrm{BO}_{3}\right)_{2}$ (KZBO) was first identified by Akella and Keszler. ${ }^{26}$ They determined the structure of the material and measured its refractive indices. Since then the compound was forgotten. In this paper, we present an insightful investigation of the luminescence of KZBO. The luminescence properties, including excitation and emission spectra, luminescence decay were reported. The photoluminescence and the persistent luminescence mechanisms were discussed based on the luminescence properties and thermoluminescence (TL) glow curve.

\section{Experimental}

School of Physics and Optoelectronic Engineering, Guangdong University of Technology, Waihuan Xi Road, No.100, Guangzhou 510006, People's Republic of China. E-mail: jugf@gdut.edu.cn; Fax: +86-20-39322265; Tel: +86-20-39322262
Powder samples of KZBO were synthesized using a high temperature solid state reaction method. Stoichiometric 
amounts of A.R. grade starting materials $\mathrm{K}_{2} \mathrm{CO}_{3}, \mathrm{ZrO}_{2}$ and $\mathrm{H}_{3} \mathrm{BO}_{3}$ were weighed and thoroughly mixed in an agate mortar. In order to prevent spewing and also to decompose the boric acid and potassium carbonate, the mixture was first heated up to $600{ }^{\circ} \mathrm{C}$ very slowly and kept at this temperature for $1 \mathrm{~h}$. After regrinding, the samples were sintered at $750{ }^{\circ} \mathrm{C}$ for $10 \mathrm{~h}$. After cooling to room temperature inside the furnace, the obtained samples were ground again for next characterizations.

Phase purity of the prepared samples were checked by powder X-ray diffraction (XRD) using a diffractometer with $\mathrm{Cu}$ $\mathrm{K} \alpha$ radiation $(\lambda=1.5406 \AA)$ at $36 \mathrm{kV}$ tube voltage and $20 \mathrm{~mA}$ tube current (Beijing PGENERAL, XD-2). Diffuse reflection spectra were obtained by a UV-visible spectrophotometer (Thermo scientific, EVOLUTION 220) using $\mathrm{BaSO}_{4}$ as a reference. The photoluminescence excitation (PLE), emission (PL) spectra and fluorescence decay curve of the samples were recorded by a fluorescence spectrophotometer (Edinburgh, FLS980). A thermoluminescent dosimeter (Guangzhou-radiation science and technology, SL08-L) was applied to measure the thermoluminescence (TL) glow curve. The persistent luminescence isothermal decay curve was obtained with a single-photon counter system (Tianjin Tuopu Instrument, WSZ-5A). Prior to the TL glow and persistent luminescence isothermal decay curve measurements, the sample was excited for 1 min by a $15 \mathrm{~W}$ low-pressure mercury discharge lamp $(254 \mathrm{~nm})$. For the TL glow curve measurement, the heating rate was $5{ }^{\circ} \mathrm{C} \mathrm{s}^{-1}$.

\section{Results and discussion}

The XRD pattern of KZBO together with the powder diffraction file (PDF) \#80-0204 is shown in Fig. 1. The XRD lines of the KZBO sample are well coincident with the standard PDF. No extra line was observed, and the entire pattern could be well indexed to KZBO single phase.

The compound KZBO is isostructural to the mineral buetschliite with a trigonal unit cell and space group $R \overline{3} m, a=$ $5.2830 \AA, c=17.5180 \AA, V=423.42 \AA^{3}$ and $Z=3 .^{25}$ The unit cell

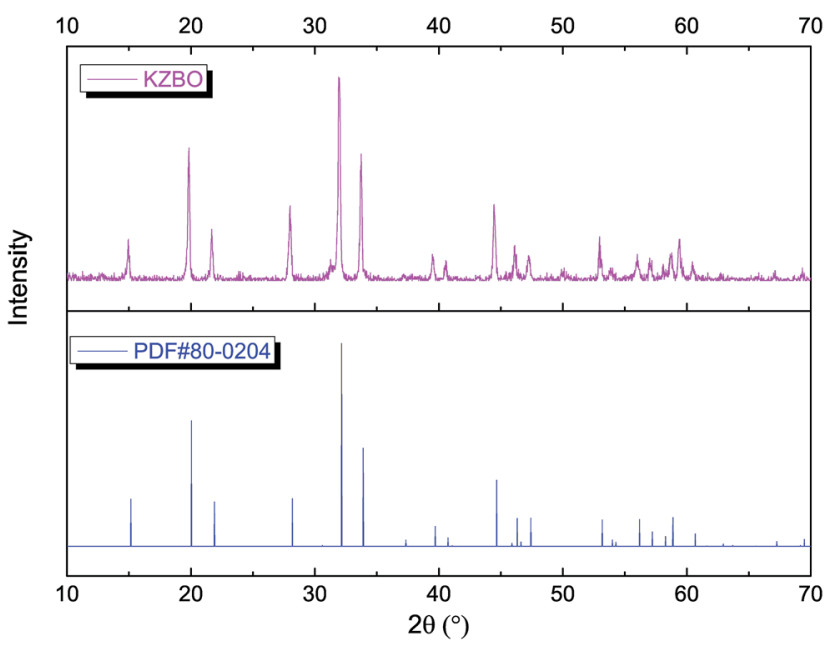

Fig. 1 The XRD patterns of KZBO and PDF\#80-0204 given for comparison.

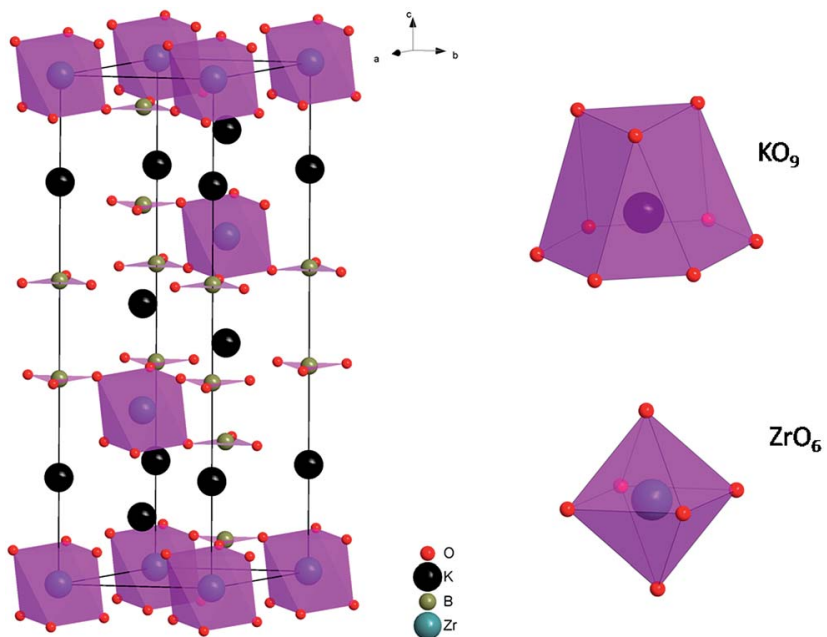

Fig. 2 Schematic view of the crystallographic structure of the unit cell of $\mathrm{KZBO}$ (left) and the coordination polyhedrons of $\mathrm{KO}_{9}$ and $\mathrm{ZrO}_{6}$ (right). ${ }^{25}$

structure of KZBO as well as the coordination polyhedrons of $\mathrm{KO}_{9}$ and $\mathrm{ZrO}_{6}$ is illustrated in Fig. $2 .{ }^{25}$ In this structure, parallel (orthogonal to the crystallographic $c$ axis) layers of flat trigonal $\mathrm{BO}_{3}$ groups build up the skeleton, and single sheets of $\mathrm{Zr}^{4+}$ and double sheets of $\mathrm{K}^{+}$are alternately interleaved into the $\mathrm{BO}_{3}$ layers. Each $\mathrm{ZrO}_{6}$ octahedron is connected with two $\mathrm{KO}_{9}$ octahedrons by sharing face which is orthogonal to the $c$ axis. The $\mathrm{ZrO}_{6}$ octahedrons within a same layer are bridged by $\mathrm{BO}_{3}$ triangles by sharing vertexes. The $\mathrm{KO}_{9}$ octahedrons within the same sheet are also bridged by $\mathrm{BO}_{3}$ triangle but there are common $\mathrm{O}$ vertices shared between the $\mathrm{KO}_{9}$ octahedrons from different sheets.

In order to investigate the energy absorption of the KZBO phosphor, diffuse reflectance spectrum is shown in Fig. 3a. The diffuse reflectance spectrum shows a near plateau of $\sim 80 \%$ reflectance in the wavelength range of $400-700 \mathrm{~nm}$ and starts to decrease from $400 \mathrm{~nm}$ to higher energy. The absorption can be attributed to the ligand to metal charge transfer (LMCT) absorption, an electron from oxygen ion is transferred to a molecular orbital which is largely localized on the zirconium ions.

The near edge relation between absorption coefficient $\alpha$ and optical band gap $E_{\mathrm{g}}$ can be described by the equation: ${ }^{26,27}$

$$
(h \nu \alpha)^{2}=A\left(h \nu-E_{\mathrm{g}}\right)
$$

where $h \nu$ represents the photon energy, $A$ is a constant. The absorption coefficient $\alpha$ in eqn (1) is proportional to the quantity $F(R),{ }^{28,29}$

$$
F(R)=\frac{(1-R)^{2}}{2 R}
$$

where $R$ is the reflectance of a thick material. The Tauc plot of $[F(R) h \nu]^{2}$ versus $h \nu$ is shown in Fig. $3 \mathrm{~b}$. The optical band gap $E_{\mathrm{g}}$ of KZBO is determined to be $5.05 \mathrm{eV}$ by Tauc method.

Fig. 4 shows the PLE and PL spectra of the LZBO sample at room temperature. Upon $295 \mathrm{~nm}$ excitation, the LZBO sample 

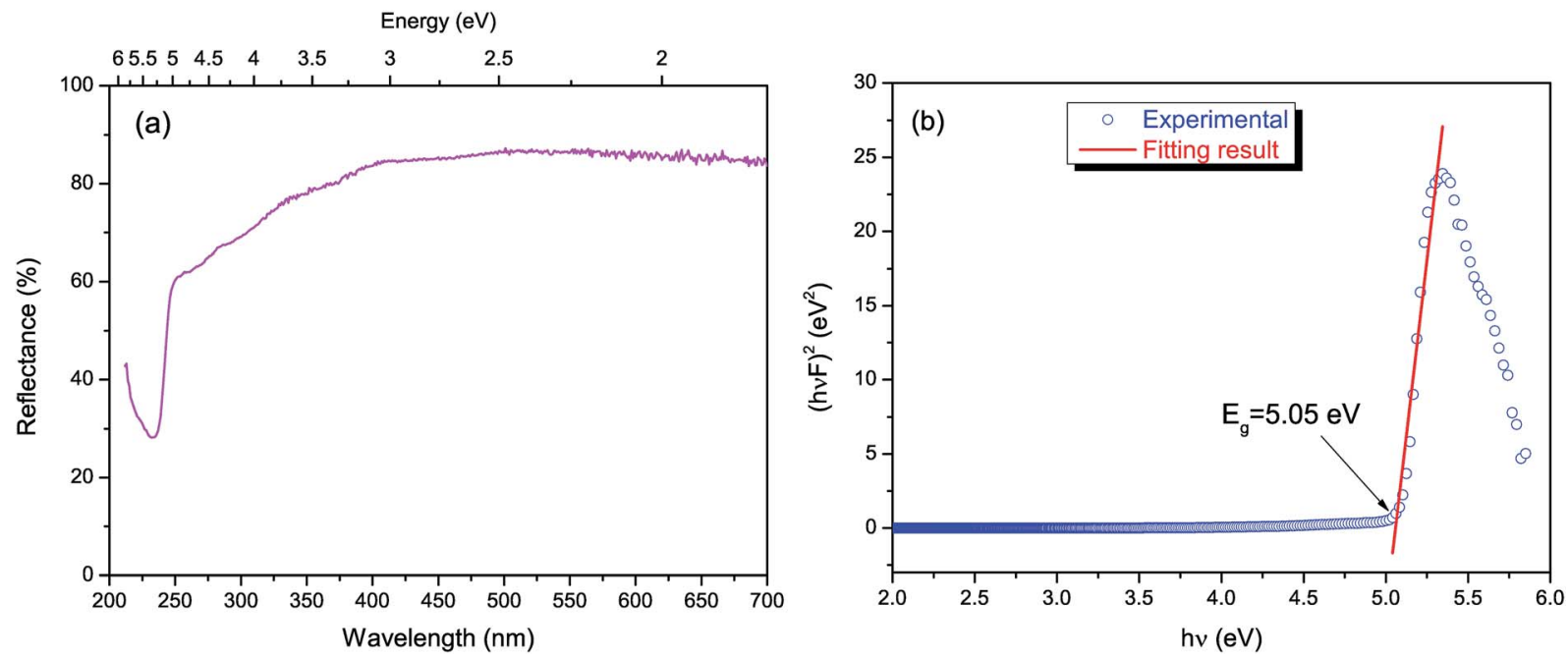

Fig. 3 (a) Diffuse reflectance spectrum of KZBO; (b) determination of the optical bandgap $\left(E_{\mathrm{g}}\right)$ using Tauc plot for KZBO.
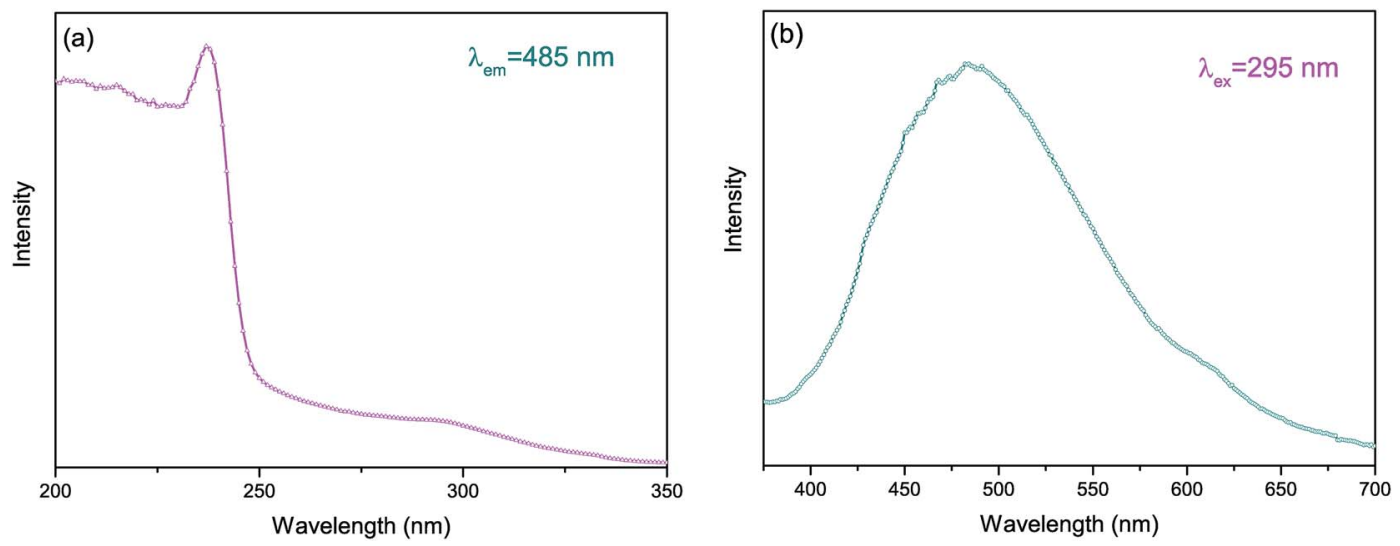

Fig. 4 The PLE (a) and PL (b) spectra of KZBO.

shows cyan luminescence with a maximum wavelength at about $485 \mathrm{~nm}$. Based on the PL spectrum, Commission Internationale de l'Eclairage (CIE) chromaticity coordinate of the sample is calculated to be $(0.232,0.313)$, which is in the cyan region. It can be ascribed to the charge transfer transition from central zirconium ion to oxygen ligands. The full width at half maximum (FWHM) of the emission band and the Stokes shift are about 5600 and $13100 \mathrm{~cm}^{-1}$, respectively. The large Stokes shift results in the mismatch between PLE and PL spectra, therefore concentration quenching is missing. The excitation spectrum by monitoring at $485 \mathrm{~nm}$ consists of two broad bands with double maxima at around 295 and $237 \mathrm{~nm}$, respectively. The excitation spectrum agrees with the reflectance spectrum. The band at $295 \mathrm{~nm}$ can be attributed to electron-hole pair creation, while the higher band at $237 \mathrm{~nm}$ is attributed to valence-conduction band charge transfer. In the former case, the electron (on the zirconium) and hole (on the oxygen) remain together. In the latter case, however, free electrons and holes are created.

Under $237 \mathrm{~nm}$ excitation, the luminescence decay curve of KZBO was measured $\left(\lambda_{\mathrm{em}}=485 \mathrm{~nm}\right)$, and the results are shown in
Fig. 5. The decay curve can be well fitted well by single exponential function $\left(R^{2}=0.998\right)$. The life time value was determined to be 5.7 $\mu \mathrm{s}$. The value is in line with similar systems. ${ }^{24,30}$

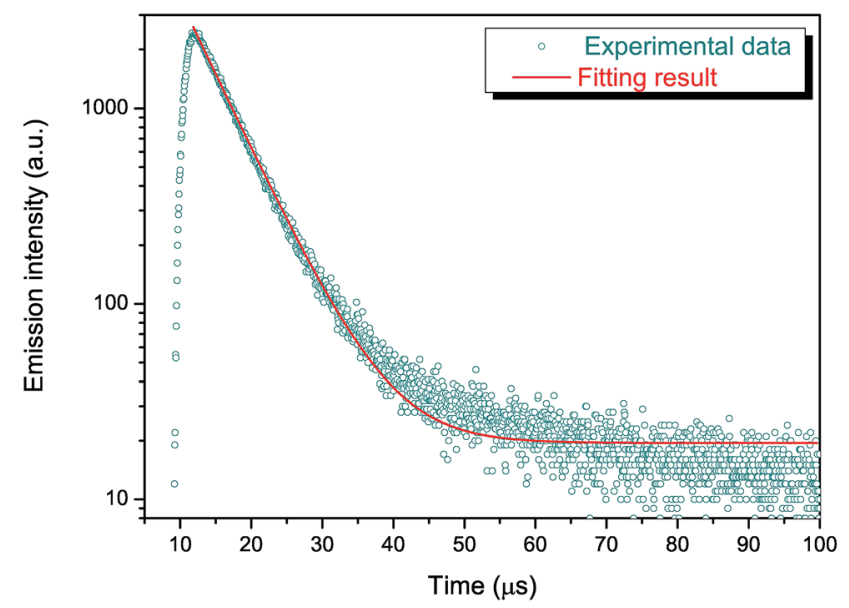

Fig. 5 The photoluminescence decay curve of KZBO and the single exponential fitting result. 


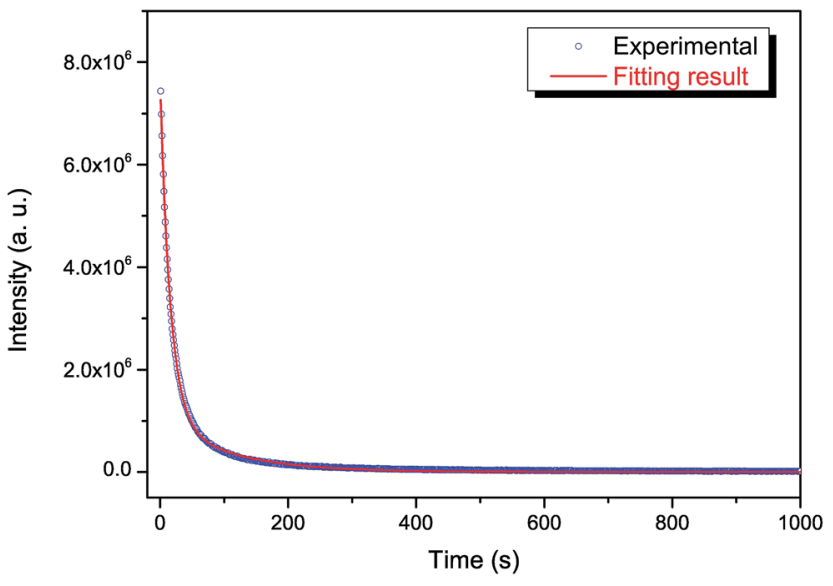

Fig. 6 The persistent luminescence isothermal decay curves of KZBO.

After ceasing the irradiation light source of $254 \mathrm{~nm}$ at room temperature, persistent luminescence was observed. Fig. 6 shows the decay curves of the persistent luminescence in the time range of 1-1000 s recorded at room temperature. The decay curve fits to single exponential functions in $0-40 \mathrm{~s}(\tau=17 \mathrm{~s})$, but to $t^{-1.4}$ power function afterwards. The decay is very fast during the first minute, but slows down later.

Persistent luminescence is a special case of thermally stimulated luminescence. The TL technique may be the only available tool for revealing the nature of traps in persistent phosphors. Fig. 7a shows the TL curve of KZBO. The TL curve consist of two main band (66 and $123{ }^{\circ} \mathrm{C}, \mathrm{T} 1$ and T2) and two minor contributions at the higher side $\left(187\right.$ and $257^{\circ} \mathrm{C}$, T3 and $\mathrm{T} 4)$. Apparently, $\mathrm{T} 1$ and $\mathrm{T} 2$ are mainly responsible for the room temperature persistent luminescence. The band shape is asymmetric with the low-temperature side narrower than the high-temperature one, indicating retrapping dominates and therefore the process is of the second order kinetics. The persistent luminescence decay profiles of these phosphors follow power law after the initial period. This also suggests second order kinetics.

In order to achieve a quantitative analysis of the TL curve, the TL curve was deconvoluted into general order components: ${ }^{31}$

$$
\begin{aligned}
I(T)= & s^{\prime} n_{0}{ }^{b} \exp (-E / k T) / \\
& {\left[1+\left((b-1) s^{\prime} n_{0}{ }^{b-1} / \beta\right) \int_{T_{0}}^{T} \exp (-E / k T) \mathrm{d} T\right]^{b /(b-1)} }
\end{aligned}
$$

where $I$ is the TL intensity, $s^{\prime}$ is a pre-exponential factor, $n_{0}$ is the concentration of trapped carriers, $b$ is the kinetic order, $E$ is the activation energy, $k$ is the Boltzmann's constant, and $\beta$ is the heating rate. The deconvolution results of just charged KZBO are tabulated in Table 1 . The kinetic order of $\mathrm{T} 1$ is 2 , confirming its second order kinetics.
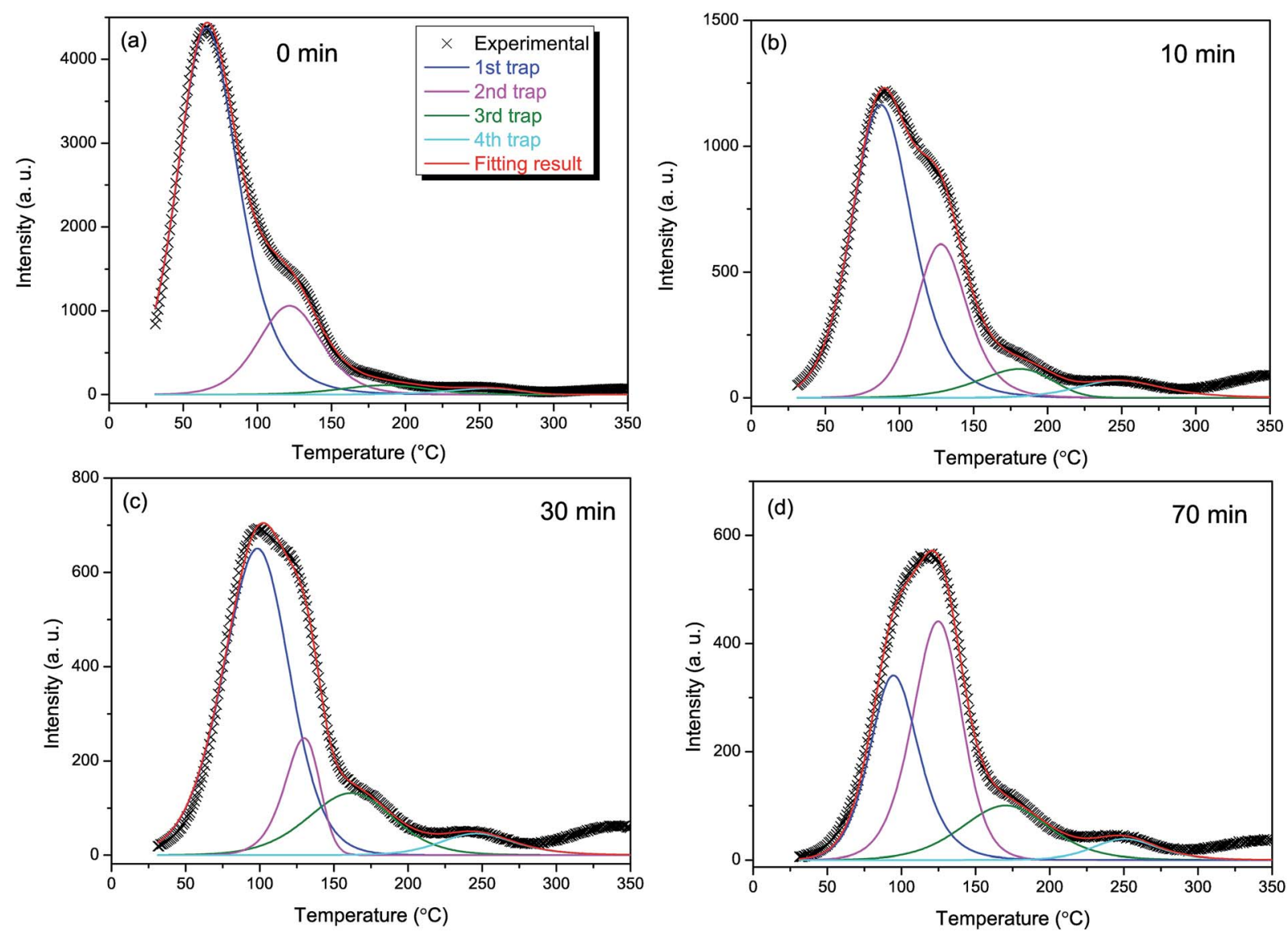

Fig. 7 The TL curves of the KZBO undergoing different decay times $(0,10,30$ and $70 \mathrm{~min})$ and the general order deconvolution results. 
Table 1 The TL parameters of just charged KZBO

\begin{tabular}{|c|c|c|c|c|c|c|c|}
\hline Traps & $E(\mathrm{eV})$ & $s\left(\mathrm{~s}^{-1}\right)$ & $n_{0}$ & $b$ & $T_{\mathrm{m}}\left({ }^{\circ} \mathrm{C}\right)$ & Height (a. u.) & Area \\
\hline $1 \mathrm{st}$ & 0.66 & $2.23 \times 10^{9}$ & 48000 & 2 & 65.8 & 4400 & $2.3 \times 10^{5}$ \\
\hline 2nd & 0.82 & $7.76 \times 10^{9}$ & 11900 & 1.74 & 122.8 & 1060 & $5.97 \times 10^{4}$ \\
\hline $3 \mathrm{rd}$ & 0.72 & $1.64 \times 10^{7}$ & 1700 & 1.45 & 186.5 & 110 & 8500 \\
\hline 4 th & 0.98 & $4.43 \times 10^{8}$ & 920 & 1 & 256.7 & 70 & 4400 \\
\hline
\end{tabular}

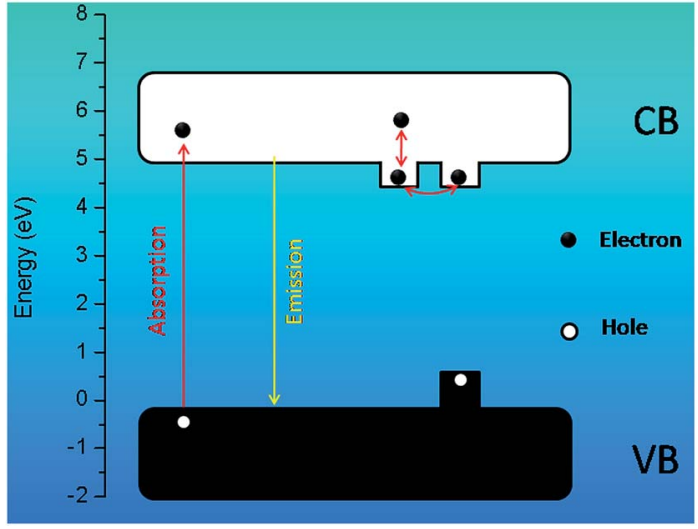

Fig. 8 Energy level scheme for luminescence in KZBO.

To investigate the detrapping process in KZBO, the TL glow curves with different delay times $(0,10,30$, and $70 \mathrm{~min})$ after excitation are recorded in Fig. 7. With the increasing of decay time, the amplitudes of T1 and T2 decreases sharply, resulting in the centroid of the whole TL band moving to higher temperature side. On the other side, however, T3 and T4 are almost intact. These traps require higher temperature to be emptied. At this stage, it is no ground to speculate the nature of the traps.

On the basis of the above results, a tentative mechanism by using an energy level scheme was proposed to illustrate the persistent luminescence in KZBO, as shown in Fig. 8. In Fig. 8, the band gap of KZBO and the trap depth are drawn according to the determined values. For the clarity to the readers, only T1 is depicted. Upon UV excitation, electrons in the valence band (VB) are excited to the conduction band (CB) and holes are left behind in VB. However, this process does not necessarily yield free carriers. ${ }^{19}$ In strong-coupled systems likes KZBO, a considerable relaxation occurs after excitation and giving up excess energy to the lattice, the electrons and holes are localized. They remain together and cannot transfer their energy to a neighbor, that why concentration quenching is absence in this phosphor. The recombination of the electrons and holes results in the emission of KZBO. Before they can fluoresce, the carriers (electrons and/or holes) may have chances to escape to the energy bands with or without the aid of phonons. The free carriers can be captured by traps with opposite charges which are from lattice defects. If the trap density is too high the carriers may migrate from one trap to another by tunneling until to a killer site. Therefore suitable trap density as well as trap depth is crucial for a persistent phosphor. The trapped carriers have chances to be free again by the thermal energy at ambient temperature. Finally the freed carriers go back to a zirconium complex and subsequently emission occurs.

\section{Conclusions}

In conclusion, a novel cyan emitting self-activated persistent phosphor KZBO has been successfully prepared via a hightemperature solid-state reaction method. The absorption properties, emission properties, persistent luminescence and TL of the sample are characterized and analyzed in detail. The bandgap of KZBO is determined to be $5.05 \mathrm{eV}$. The persistent luminescence originates from the charge transfer in the zirconium complex. Under UV light excitation, the phosphor shows a broad emission band located at $\sim 485 \mathrm{~nm}$. The depth of dominating trap responsible for the room temperature persistent luminescence is $0.66 \mathrm{eV}$. Although the physical nature of the traps is still unclear, the trap type can be revealed in future conductivity and Hall measurements.

\section{Acknowledgements}

This work is financially supported by the National Natural Science Foundation of China (No. 21271049).

\section{References}

1 Z. Pan, Y. Y. Lu and F. Liu, Nat. Mater., 2011, 11, 58-63.

2 H. F. Brito, J. Hölsä, T. Laamanen, M. Lastusaari, M. Malkamäki and L. C. V. Rodrigues, Opt. Mater. Express, 2012, 2, 371-381.

3 K. Van den Eeckhout, P. F. Smet and D. Poelman, Materials, 2010, 3, 2536-2566.

4 A. Jain, A. Kumar, S. J. Dhoble and D. R. Peshwe, Renewable Sustainable Energy Rev., 2016, 65, 135-153.

5 T. Matsuzawa, Y. Aoki, N. Takeuchi and Y. Murayama, J. Electrochem. Soc., 1996, 143, 2670-2673.

6 H. Yamamoto and T. Matsuzawa, J. Lumin., 1997, 72-74, 287289.

7 Y. Lin, Z. Tang and Z. Zhang, Mater. Lett., 2001, 51, 14-18.

8 Y. Lin, Z. Tang, Z. Zhang, X. Wang and J. Zhang, J. Mater. Sci. Lett., 2001, 20, 1505-1506.

9 C. C. S. Pedroso, J. M. Carvalho, L. C. V. Rodrigues, J. Hölsä and H. F. Brito, ACS Appl. Mater. Interfaces, 2016, 8, 1959319604.

10 Y. Pan, L. Li, J. Lu, R. Pang, L. Wan and S. Huang, Dalton Trans., 2016, 45, 9506-9512. 
11 H. Guo, Y. Wang, W. Chen, W. Zeng, G. Li and Y. Li, New J. Chem., 2016, 40, 613-618.

12 Q. le Masne de Chermont, C. Chanéac, J. Seguin, F. Pellé, S. Maîtrejean, J. P. Jolivet, D. Gourier, M. Bessodes and D. Scherman, Proc. Natl. Acad. Sci. U. S. A., 2007, 104, 9266-9271.

13 A. M. Smith, M. C. Mancini and S. Nie, Nat. Nanotechnol., 2009, 4, 710-711.

14 A. Bessière, S. Jacquart, K. Priolkar, A. Lecointre, B. Viana and D. Gourier, Opt. Express, 2011, 19, 10131-10137.

15 W. Yan, F. Liu, Y.-Y. Lu, X.-J. Wang, M. Yin and Z. Pan, Opt. Express, 2010, 18, 20215-20221.

16 D. Jia, L. A. Lewis and X.-J. Wang, Electrochem. Solid-State Lett., 2010, 13, J32-J34.

17 F. Liu, W. Yan, Y.-J. Chuang, Z. Zhen, J. Xie and Z. Pan, Sci. Rep., 2013, 3, 1554.

18 C. R. Ronda, Luminescence: from theory to applications, WileyVCH, Weinheim, 2008.

19 G. Blasse and B. C. Grabmaier, Luminescent materials, Springer-Verlag, Berlin, New York, 1994.

20 C. B. Liu and G. B. Che, Chin. J. Inorg. Chem., 2006, 22, 503506.
21 T. Wang, J. Gou, X. Xu, D. Zhou, J. Qiu and X. Yu, Opt. Express, 2015, 23, 12595-12604.

22 P. Feng, J. Zhang, C. Wu, X. Liu and Y. Wang, Mater. Chem. Phys., 2013, 141, 495-501.

23 Y. Guan, L. Qin, Y. Huang, C. Qin, D. Wei and H. J. Seo, Mater. Res. Bull., 2014, 54, 24-27.

24 G. Ju, Y. Hu, L. Chen, Y. Jin, S. Zhang, F. Xue and H. Chen, Mater. Res. Bull., 2016, 83, 211-216.

25 A. Akella and D. A. Keszler, Inorg. Chem., 1994, 33, 15541555.

26 J. Tauc, R. Grigorovici and A. Vancu, Phys. Status Solidi, 1966, 15, 627-637.

27 M. A. Omar, Elementary solid state physics : principles and applications, Addison-Wesley Pub. Co., Reading, Mass., 1975.

28 E. L. Simmons, Appl. Opt., 1975, 14, 1380-1386.

29 J. H. Nobbs, Rev. Prog. Color. Relat. Top., 1985, 15, 66-75.

30 C. W. Park and H. J. Seo, Ceram. Interfaces, 2014, 40, 24952499.

31 S. W. S. McKeever, Thermoluminescence of solids, Cambridge University Press, New York, 1985. 